\title{
Erratum
}

\section{Erratum: Yao et al., "Platelet-Derived Growth Factor B Chain Is a Novel Target Gene of Cocaine-Mediated Notch1 Signaling: Implications for HIV-Associated Neurological Disorders"}

In the article "Platelet-Derived Growth Factor B Chain Is a Novel Target Gene of Cocaine-Mediated Notch1 Signaling: Implications for HIV-Associated Neurological Disorders," by Honghong Yao, Ming Duan, Guoku Hu, and Shilpa Buch, which appeared on pages 12449-12454 of the August 31, 2011 issue, on page 12452, within Figure 4D, an erroneous image of the Western blot for $\beta$-actin in the left and right panels was included. This error does not affect the conclusions of the article. The authors regret the error. The updated Figure 4 is below.

A
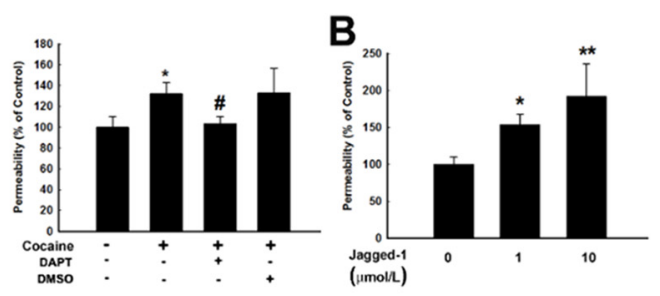

D
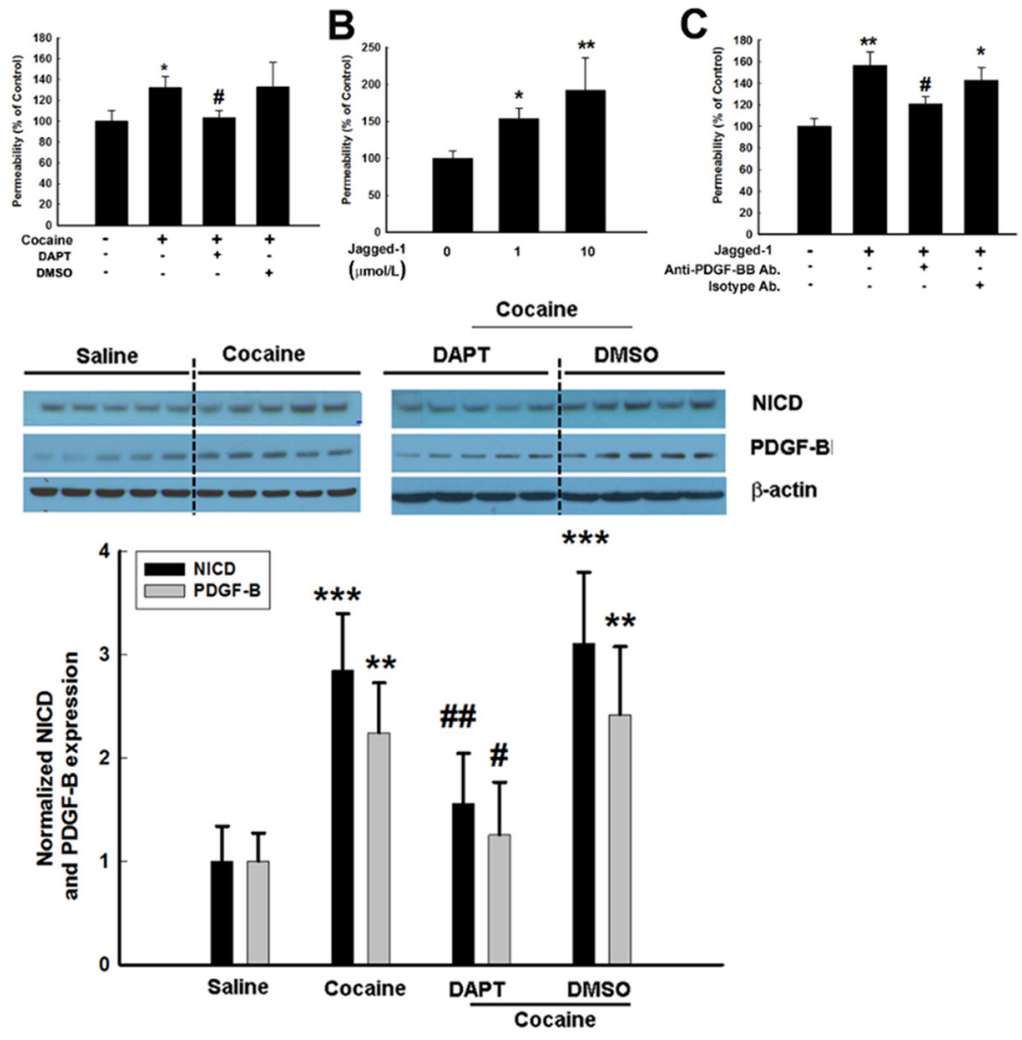

E

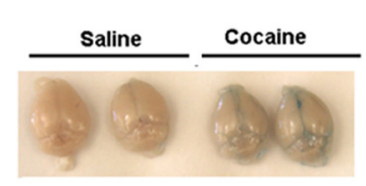

$\mathbf{F}$



G

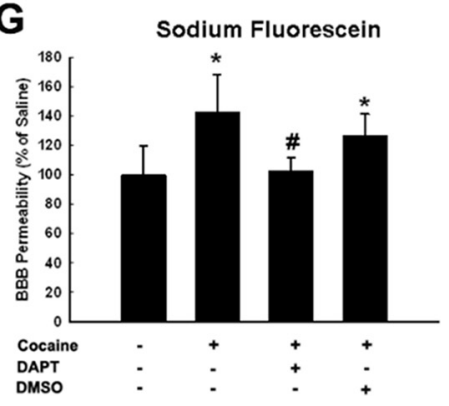

Figure 4. 